\title{
Increased disease activity in a patient with sarcoidosis after high dose interleukin 2 treatment for metastatic renal cancer
}

\section{T F Logan, E S Bensadoun}

Thorax 2005;60:610-611. doi: 10.1136/thx.2004.024018

Sarcoidosis is a disease of unknown aetiology in which cytokines such as interleukin 2 (IL-2) are thought to play an important role. We present the case history of a 48 year old man with sarcoidosis who received treatment with high dose IL-2 for metastatic renal cell cancer, following which he developed hypercalcaemia characterised by a raised level of 1,25-dihydroxyvitamin $D\left(1,25-(\mathrm{OH})_{2}-\mathrm{D}_{3}\right)$, a finding consistent with sarcoidosis associated hypercalcaemia. The increased activity in his sarcoidosis following IL-2 treatment provides direct supportive evidence for the role of IL- 2 in the pathogenesis of sarcoidosis.

$\mathrm{S}$ arcoidosis is a disease in which cytokines such as interleukin 2 (IL-2) are thought to play an important role. ${ }^{1}$ We present the case history of a patient with sarcoidosis who developed an increase in activity of the disease, as manifested by hypercalcaemia, following IL-2 treatment for metastatic renal carcinoma.

\section{CASE REPORT}

A 48 year old white man presented with fatigue lasting several months and a rising haematocrit level. A CT scan of the abdomen revealed a mass in the left kidney consistent with renal cell carcinoma. Preoperative staging CT of the chest showed a diffuse micronodular pattern and enlarged pretracheal lymph nodes (fig 1). Mediastinoscopy and a thoracoscopic wedge biopsy of the lung revealed only nonnecrotising granulomatous inflammation with negative special stains and negative cultures for fungus and mycobacteria. The patient underwent a left nephrectomy and was found to have a clear cell renal carcinoma contained within Gerota's fascia. Abdominal para-aortic lymph nodes showed no evidence of tumour but did show non-necrotising granulomatous inflammation. The postoperative recovery was uneventful with resolution of the patient's fatigue and erythrocytosis.

A diagnosis of pulmonary sarcoidosis had been made preoperatively based on the radiographic findings, the presence of non-necrotising granulomas, and the absence of granulomatous infection. The patient's evaluation was completed 6 weeks after surgery and, at that time, his pulmonary function tests were normal, the serum angiotensin converting enzyme (ACE) level was 119 IU/1 (normal 9$67 \mathrm{IU} / \mathrm{l})$, total calcium was $10.1 \mathrm{mg} / \mathrm{dl}$, serum creatinine $1.4 \mathrm{mg} / \mathrm{dl}^{*}$, and an ophthalmological examination was normal. No treatment for his sarcoidosis was started and he remained asymptomatic for 9 months with stable pulmonary function tests, laboratory data, and CT scans. Nine months

${ }^{*}$ Conversion factors for SI units: creatinine: $\times 88.4 \mu \mathrm{mol} / \mathrm{l}$; albumin: $\times 10 \mathrm{~g} / \mathrm{l}$; calcium (total): $\times 0.25 \mathrm{mmol} / \mathrm{l}$; calcium (ionised): $\times 0.25 \mathrm{mmol} / /$; $1,25-(\mathrm{OH})_{2}-\mathrm{D}_{3}$ : $\times 2.40 \mathrm{pmol} / \mathrm{l}$. after the nephrectomy he developed some fatigue and a CT scan of the chest revealed several new enlarging nodules in both lung bases (fig 2). A wedge resection of one of the new pulmonary nodules demonstrated metastatic clear cell adenocarcinoma. A CT scan of the abdomen and a bone scan were negative for metastatic disease.

The patient was then evaluated for IL-2 treatment for his metastatic renal carcinoma. Before treatment his creatinine level was $1.5 \mathrm{mg} / \mathrm{dl}$, total calcium $9.0 \mathrm{mg} / \mathrm{dl}$, serum albumin $3.8 \mathrm{~g} / \mathrm{dl}$, and ACE $123 \mathrm{IU} / \mathrm{l}$. The patient was treated with high dose IL-2 (600 000 international units (IU) intravenous bolus every 8 hours) and tolerated a total of 10 doses during his first week of treatment. He then developed some late onset fever and was treated with antibiotics at home for 2 weeks before being readmitted for his second week of IL-2 treatment. On readmission laboratory tests showed the following results: total calcium $11.4 \mathrm{mg} / \mathrm{dl}$, ionised calcium $6.1 \mathrm{mg} / \mathrm{dl}$ (normal 4.5-5.3 mg/dl), creatinine $1.9 \mathrm{mg} / \mathrm{dl}$, ACE $111 \mathrm{IU} / \mathrm{l}$; his chest radiograph was unchanged from baseline. The parathyroid hormone (PTH) level and PTH related protein level were normal, but the level of 1,25-dihydroxyvitamin D ( $\left.1,25-(\mathrm{OH})_{2}-\mathrm{D}_{3}\right)$ was $103 \mathrm{pg} / \mathrm{ml}$ (normal 15-75 pg/ $\mathrm{ml}$ ). After intravenous hydration the total calcium level fell to $9.2 \mathrm{mg} / \mathrm{dl}$ and the creatinine level fell to $1.7 \mathrm{mg} / \mathrm{dl}$. The patient was then treated with IL-2 with the same dose and schedule but only tolerated four doses.

After discharge his total calcium once again increased and remained persistently raised at $11.7-11.8 \mathrm{mg} / \mathrm{dl}$, serum albumin was in the range $2.9-3.5 \mathrm{~g} / \mathrm{dl}$, creatinine $2.2-$ $2.4 \mathrm{mg} / \mathrm{dl}$, and the ACE level was $143 \mathrm{IU} / \mathrm{l}$. Treatment for sarcoidosis related hypercalcaemia was started with hydroxychloroquine $400 \mathrm{mg}$ daily. Hydroxychloroquine rather than prednisone was chosen because of the possible inhibition of the anti-tumour effects of IL-2 by prednisone. Two weeks after starting hydroxychloroquine the $1,25-(\mathrm{OH})_{2}-\mathrm{D}_{3}$ level had fallen to $78 \mathrm{pg} / \mathrm{ml}$ and at 6 months follow up on hydroxychloroquine treatment the total calcium was

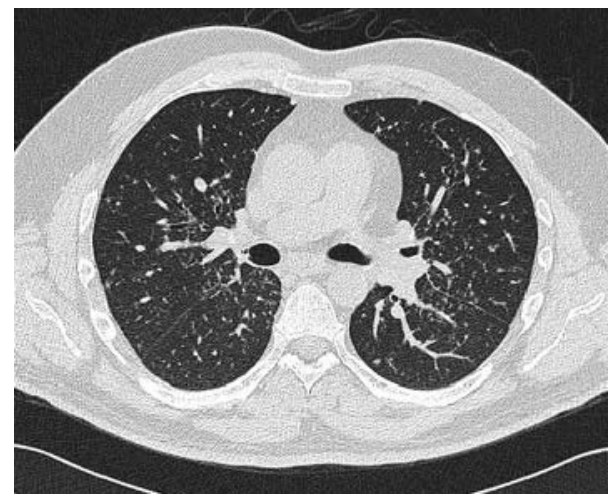

Figure 1 Chest CT scan showing a bilateral micronodular pattern with a bronchovascular distribution. 


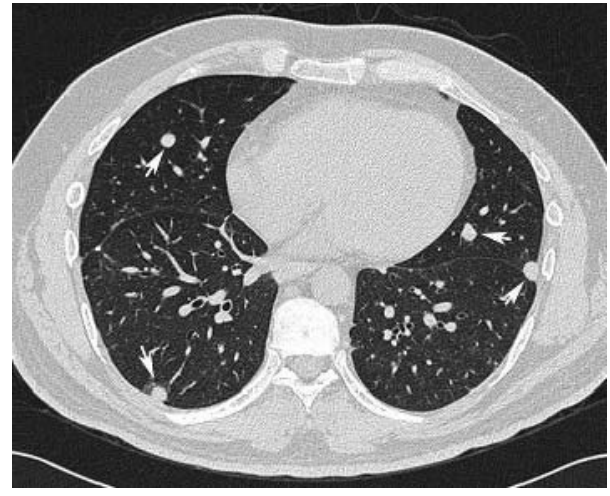

Figure 2 Chest CT scan performed 9 months after the nephrectomy showing multiple new lower lobe nodules (arrowheads).

$10.4 \mathrm{mg} / \mathrm{dl}$, serum albumin $3.7 \mathrm{~g} / \mathrm{dl}$, creatinine $1.6 \mathrm{mg} / \mathrm{dl}$, $1,25-(\mathrm{OH})_{2}-\mathrm{D}_{3} 73 \mathrm{pg} / \mathrm{ml}$, ACE $108 \mathrm{IU} / \mathrm{l}$, the CT scan showed stable disease, and a bone scan remained negative.

\section{DISCUSSION}

Sarcoidosis is a multisystem disease characterised by nonnecrotising granulomatous inflammation. The aetiology remains unknown, but the production of cytokines by $\mathrm{T}$ lymphocytes and macrophages plays a critical role in the pathogenesis of the granulomatous inflammation. Cytokines implicated in sarcoidosis include IL-1, IL-2, IL-4, IL-5, IL-6, IL-8, IL-9, IL-10, IL-12, IL-13, IL-15, IL-16, interferon- $\gamma$ (IFN$\gamma$ ), transforming growth factor- $\beta$ (TGF- $\beta$ ), tumour necrosis factor- $\alpha($ TNF- $\alpha)$, and chemokines. ${ }^{1-3}$

The lungs of sarcoidosis patients have an increased number of CD4+ T lymphocytes that can be subdivided into two groups based on their pattern of cytokine production. T helper 1 (Thl) cells produce IL-2, IL-12, IFN- $\gamma$, and lymphotoxin which are mainly involved in cell mediated immunity, while T helper 2 (Th2) cells produce IL-4, IL-5, IL9, IL-10, and IL-13 which are primarily involved in humoral immunity. ${ }^{1-3}$ In sarcoidosis the Thl cytokine pattern seems to predominate in areas of granuloma formation, and it is the balance between Thl and Th2 cytokines that may influence the outcome of the granulomatous inflammation characteristic of sarcoidosis. ${ }^{1-3}$ It has been postulated that a Thl predominant pattern may be more important in promoting granulomatous inflammation while a Th2 predominant pattern may be more involved in the development of fibrosis. ${ }^{3}$

IL-2, a Thl cytokine, plays an important role in the pathogenesis of the granulomatous inflammation in sarcoidosis. $^{12}$ Studies have shown that IL-2 mRNA and protein levels are higher in lung cells and the bronchoalveolar lavage (BAL) fluid of patients with sarcoidosis. ${ }^{2}$ Other studies have shown that sarcoidosis patients with higher levels of IL-2 secretion by BAL cells or higher serum levels of soluble IL-2 receptor may be more likely to have progressive disease. ${ }^{1}{ }^{4}$

There have been previous case reports of two HIV positive patients who developed sarcoidosis following treatment with subcutaneous IL-2; ${ }^{7}$ however, our case is the first to describe the effect of IL-2 treatment in a patient with pre-existing sarcoidosis. Our patient had an increase in sarcoidosis disease activity as manifested by new onset hypercalcaemia shortly after receiving IL-2 for his metastatic renal carcinoma. The findings of an increased level of 1,25- $(\mathrm{OH})_{2}-\mathrm{D}_{3}$, a normal PTH related protein level, and a normal bone scan were most consistent with a diagnosis of hypercalcaemia secondary to sarcoidosis than metastatic renal cell cancer.

Hypercalcaemia occurs in about $10 \%$ of patients with sarcoidosis and is the result of increased conversion of 25dihydroxyvitamin $\mathrm{D}$ to the metabolically active 1,25-dihydroxyvitamin D by activated pulmonary macrophages and granulomatous tissue. ${ }^{9}$ The enzyme that catalyses this conversion is 25 -hydroxyvitamin $\mathrm{D}_{3} 1 \alpha$-hydroxylase which can be inhibited by hydroxychloroquine, the drug used to treat our patient. A recent study has shown that mRNA levels for 25-hydroxyvitamin $D_{3} 1 \alpha$-hydroxylase are increased in the BAL fluid cells of sarcoidosis patients, and that the levels seem to correlate with disease activity. ${ }^{10}$ These findings, coupled with previous observations that 1,25-dihydroxyvitamin D can suppress T lymphocyte proliferation, reduce IFN- $\gamma$ production, and reduce the activity of IL- 2 has led to the speculation that the overproduction of 1,25-dihydroxyvitamin D may serve to downregulate cytokine mediated inflammation in the autocrine-paracrine feedback loop. ${ }^{111}$

The development of hypercalcaemia in our patient following high dose IL-2 treatment supports the notion that IL-2 plays a key role in the granulomatous inflammation of sarcoidosis. In addition, the raised level of 1,25-dihyroxyvitamin D following IL-2 administration is consistent with the hypothesis that 1,25-dihyroxyvitamin D may be produced, in part, to regulate the effects of IL-2.

\section{Authors' affiliations}

T F Logan, Division of Hematology/Oncology, Indiana University School of Medicine, Indianapolis, IN, USA

E S Bensadoun, Division of Pulmonary and Critical Care Medicine, University of Kentucky, Lexington, KY, USA

Correspondence to: Dr E S Bensadoun, University of Kentucky, Division of Pulmonary and Critical Care Medicine, 740 South Limestone, K528 Kentucky Clinic, Lexington, KY 40536-0284, USA; ebens0@uky.edu

Received 28 February 2004

Accepted 14 May 2004

\section{REFERENCES}

1 Ziegenhagen MW, Muller-Quernheim J. The cytokine network in sarcoidosis and its clinical relevance. J Intern Med 2003;253:18-30.

2 Moller DR. Cells and cytokines involved in the pathogenesis of sarcoidosis. Sarcoidoisis Vasc Diffuse Lung Dis 1999;16:24-31.

3 Agostini C, Semenzato G. Cytokines in sarcoidosis. Semin Respir Infect 1998; 13:184-96.

4 Ziegenhagen MW, Rothe ME, Schlaak M, et al. Bronchoalveolar and serological parameters reflecting the severity of sarcoidosis. Eur Respir J 2003;21:407-13

5 Grutters JC, Fellrath JM, Mulder L, et al. Serum soluble interleukin-2 receptor measurements in patients with sarcoidosis. Chest 2003;124:186-95.

6 Blanche P, Gombert B, Rollot F, et al. Sarcoidosis in a patient with acquired immunodeficiency syndrome treated with interleukin-2. Clin Infect Dis 2000;31:1493-4

7 Naccache JM, Antoine M, Wislez M, et al. Sarcoid-like pulmonary disorder in human immunodeficiency virus-infected patients receiving antiretroviral therapy. Am J Respir Crit Care Med 1999;159:2009-13.

8 Sharma OP. Vitamin D, calcium, and sarcoidosis. Chest 1996;109:535-9.

9 Conron M, Young C, Beynon HLC. Calcium metabolism in sarcoidosis and its implications. Rheumatology 2000;39:707-13.

10 Invi N, Murayama A, Sasaki S, et al. Correlation between 25-hydroxyvitamin D3 $1 \alpha$-hydroxylase gene expression in alveolar macrophages and the activity of sarcoidosis. Am J Med 2001;1 10:687-93.

11 Gardner DG. Hypercalcemia and sarcoidosis: another piece of the puzzle falls into place. Am J Med 2001;110:736-7. 